\title{
Tangence
}

\section{Une rencontre entre nature et culture (Betsi Larousse ou l’ineffable eccéité de la loutre, de Louis Hamelin)}

\section{Céline Leclerc}

Numéro 49, décembre 1995

Les littératures francophones de l'Afrique et des Antilles

URI : https://id.erudit.org/iderudit/025882ar

DOI : https://doi.org/10.7202/025882ar

Aller au sommaire du numéro

Éditeur(s)

Tangence

ISSN

0226-9554 (imprimé)

1710-0305 (numérique)

Découvrir la revue

Citer ce compte rendu

Leclerc, C. (1995). Compte rendu de [Une rencontre entre nature et culture (Betsi Larousse ou l'ineffable eccéité de la loutre, de Louis Hamelin)]. Tangence, (49), 119-120. https://doi.org/10.7202/025882ar d'utilisation que vous pouvez consulter en ligne. 


\title{
Une rencontre entre nature et culture
}

\author{
Louis Hamelin, Betsi Larousse ou l'ineffable eccéité \\ de la loutre, Montréal, XYZ éditeur, coll. «Romani- \\ chels ", 1994, $271 \mathrm{p}$.
}

"Tout a commencé avec cet orignal qui est venu atterrir dans mon auto. "C'est de cette façon que Marc Carrière entame le récit de son aventure de trois jours en Haute-Mauricie. Après la rencontre accidentelle d'un orignal, ce sont les retrouvailles imprévues avec un original qui bouleverseront ses projets. Il tombe par hasard sur un ancien ami, Yvan Lépine, explorateur et fou amoureux de Betsi Larousse, chanteuse country-pop. Cet ami excentrique qui vit sans compromis et recherche inlassablement l'eccéité l'engagera à nouveau dans un périple où les émotions et les remises en question seront nombreuses.

Ce quatrième roman de Louis Hamelin, certainement plus sobre que La rage dans ses déferlements lyriques, reprend toutefois des éléments qui semblent chers à l'auteur, entre autres: le narrateur créateur, le désir pour une belle fragile, le copain "faire-valoir" et le nécessaire contact à la nature. Le narrateur, qui ne mâche pas ses mots, pose toujours un regard lucide, parfois cynique, sur ce qui l'entoure et sur la société en général. D'ailleurs, la constatation d'une déculturation causée par la suprématie de la culture de masse, déjà présente en filigrane dans les premiers romans, occupe une place prépondérante dans ce récit. On peut lire: aLes festivals, affirma l'homme gravement, sont le dernier refuge de la culture à la campagne. Eux seuls arrivent encore à retarder le déclin moral des régions. "La culture subit son procès. Dans la même veine, le narrateur mythomane des précédents romans laisse place à un narrateur dont le potentiel de fabulation se trouve en grande partie désamorcé par les médias qui créent et détruisent des mythes pour répondre aux exigences de la cote d'écoute et du tirage. Dès les premières pages, la déception est perceptible: "Je n'avais pas le choix de ma Betsi, elle m'était imposée en partage, la pulpeuse et bandante, sous les mêmes espèces qu'à tous les autres, sa version courante pour consommation rapide, produit du mystère et de la démythification automatique [...]", fini le temps où l'on s'invente 
un mythe à la hauteur de ses attentes: voici l'ère du mythe instantané.

Les préoccupations liées au temps sont très présentes dans Betsi Larousse. Au départ, le personnage de Betsi, qui doit son succès autant, sinon plus, à un bon timing qu'à son talent, révèle combien il faut être en avance sur son temps, mais pas trop, pour réussir. Yvan Lépine, quant à lui, s'apparente à un anachronisme vivant avec ses projets et ses valeurs à contre-courant de l'époque où il doit évoluer. Finalement, la démarche artistique de Marc Carrière est hantée par la question de la durée. Il travaille "concept": un work in progress voué à la décomposition, des sculptures faites de matériaux récupérés et, son ultime projet, une installation "flottante et postindustrielle" qui devrait connaitre un destin inhabituel pour une œuvre d'art.

Betsi Larousse est un roman intelligent, où l'humour, l'amitié, le désir et la nostalgie happent le lecteur dans un récit teinté de folie et de vérité. Des petits moments anodins du quotidien, par le biais d'un regard fin et sensible à la beauté des choses, y prennent une nouvelle dimension qui saura séduire grâce à son authenticité. 